\title{
How the 'West' can Overcome Unhealthy Behaviours to Prevent Chronic Diseases
}

\section{Toru Takahashi, RB Singh*, Fabien De Meester, and Douglas Wilson}

The Tsim Tsoum Institute, Krakow, Poland

Nutritional transition from Homo sapiens to Homo economicus and finally to Homo modestis needs substantial changes in the outlook of Western society, governments and industry as well as in the methods of health education that can cause changes in the health behaviour for prevention of non-communicable diseases (NCDs) (Figure 1). The causes of death among Homo sapiens, Homo erectus and Huntergatherer societies were mainly injury and accidents, whereas among modern men $80 \%$ of deaths occur due to NCDs [1-3]. It is interesting that the pandemic of tobacco, alcohol and ultra-processed food as well as drinks by the industry and the governments among Homo economicus countries is not yet realized by many in Western societies [2] but some progress is being made, albeit on a relatively small scale. Therefore, the sale and promotion of tobacco, alcohol, and ultra-processed food and drink (unhealthy commodities), transnational corporations are major drivers of global epidemics of deaths due to NCDs [1-3]. A recent study from lower middle-income country-India shows that $57.0 \%$ of deaths in adults (aged 25-64 years) were due to CVDs and other chronic diseases, $25.5 \%$ due to communicable diseases and $15.9 \%$ due to injury and accidents, indicating that our findings on deaths due to NCDs are similar to WHO estimates $[1,4]$. These trends indicate that the lower and middle income societies as well as the developed societies of the world, are following the Western Homo economicus societies [1-4].

It is interesting to know from new data from United States, that there is wealth without cardiovascular health in America [5-7]. The whole world is likely to have the same scenario in the near future unless WHO changes its outlook about wealth. Similar to American societies, many other affluent societies in various global regions have increasingly seen inequities in people's life conditions and declining social mobility and social cohesion resulting in unhealthy diet, occupational stress and sedentary behaviour leading to poor total health [3-10]. Progress can be made in reducing health inequities based on global evidence and recommending policies that reduce the health divide across all countries, including those with low incomes [1-4]. An important objective should be to find out the social determinants of health, across the life course of all societies, and in prevailing wider social and economic spheres, to achieve greater health equity and protect future generations in all our societies.

After its victory in the World War II, United States made tremendous progress in the last 4 decades, in science, industry and socioeconomic conditions, that leading to eradication/reduction of communicable diseases and good physical health at a cost of poor social, mental and spiritual health. There was a race in the whole world to follow United States, in developing warheads and other nuclear weapons, as well as industry, even in lower middle income countries and societies like China and India who made the nuclear bomb despite poverty and ignorance among one third of its societies. The budget for health expenditure in India and China remained one third of that in United States which created over-confidence among policy makers, as if money can provide much better health than a good public health policy. Apart from armaments, societies and politicians all over the world follow United States in every other aspect; including industrialization as well as in the methods of urbanization, Hollywood film, fashion and foods whatever it may be. It is important that American society should create a model in total health including; physical, social, mental and spiritual, although the US continues to be the best in research in these areas. The health budget in USA was US $\$ 2.7$ trillion in 2011 , which is $\$ 8700$ for every person in the country, and represents $17.9 \%$ of the economy, that is far greater than any other economically advanced country $[6,7]$.

Unfortunately, last week, American societies, health-care workers, and policy makers received shocking news which became world news [5-7]. It was interesting to note that despite spending more on health care per person than other high-income countries, many people in United States, die sooner, are least likely to reach the age of 50 years, and have higher rates of disease or injury. Unfortunately, Americans are less healthy from birth to 75 years of age than people in 16 other economically wealthy countries, if judged by health alone. This health disadvantage has been getting worse for 30 years, especially among women, as disclosed in a report released on January 9 from the US National Research Council and Institute of Medicine [6]. This report compared comprehensive mortality and morbidity data from USA with affluent democratic countries; Australia, Canada, France, Italy, most of the Nordic countries, Spain, and the UK. Life expectancy is shorter at birth for American men than for men in any of the other 16 countries, and American women fare little better. Surprisingly, Denmark is the only country that has a lower life expectancy for women at birth. In nine key areas of health; infant mortality and low birth weight; injuries and homicides; teenage pregnancies and sexually transmitted infections; HIV/AIDS prevalence; drug-related deaths; obesity and diabetes; heart disease; chronic lung disease; and disability, United States fare least well, or is near the bottom of the tables. This health disadvantage applies to those with health insurance, a college education, higher incomes, and healthy behaviours as well as to those without. Unfortunately or fortunately, we share the same views [8] and reported that poverty is not the absolute cause of deaths due to noncommunicable diseases (NCDs). This seminal work was rejected by several leading journals because the referees may have presumed that whatever is concluded in the United Nations High Level Meeting (UNHLM) is final and Singh and co-workers are 'unwise' to criticize it [4]. But "Satya Mev Jaytey" or truth always wins [8]. Surprisingly, WHO is a party to conclusions made at UN-HLM without any serious objections? We must share our views with American society to pressurise policy makers that United States is moving in a wrong direction regarding

*Corresponding author: RB Singh, The Tsim Tsoum Institute, Krakow, Poland, E-mail: rbs@tsimtsoum.net

Received February 22, 2013; Accepted February 22, 2013; Published February 28, 2013

Citation: Takahashi T, Singh RB, Meester FD, Wilson D (2013) How the 'West' can Overcome Unhealthy Behaviours to Prevent Chronic Diseases. J Socialomics 2: e114. doi:10.4172/2167-0358.1000e114

Copyright: (c) 2013 Takahashi T, et al. This is an open-access article distributed under the terms of the Creative Commons Attribution License, which permits unrestricted use, distribution, and reproduction in any medium, provided the original author and source are credited. 
Citation: Takahashi T, Singh RB, Meester FD, Wilson D (2013) How the 'West' can Overcome Unhealthy Behaviours to Prevent Chronic Diseases. J Socialomics 2: e114. doi:10.4172/2167-0358.1000e114

Page 2 of 3

social, mental and spiritual health as well as about physical health of the society and populations and learn lesions from experience of other countries, societies and international experts. Nuclear weapons can protect and prevent wars and injury, as in case of India and Pakistan but cannot be a good example of prosperity, to follow for providing better health despite enormous wealth, particularly better social, mental and spiritual health [1-10]. Many affluent countries such as Australia, Canada, Nordic countries, Spain etc do not have nuclear weapons, but are not inclined to consider health as a business but, a service to people by having better public health policies. Unfortunately, these countries are not in a position to provide health care policy to USA because this has to be the duty of the American society, although Paul Dudley White, the great American physician in the last century, also failed, to curve capitalist approaches [11]. The United States has been a leader in many beneficial developments in society especially since WWII but in recent decades its society has not been the recipient of its potential to counter NCDs and now, more than ever, is a time to reverse adverse policies and create a healthier society.

Unfortunately, we know what the causes of deaths due to NCDs are, but do not share and dare to have political will and agenda to curve health behaviour of the societies for achieving millennium

The Tsim Tsoum Concept \& Evolutionary Diet

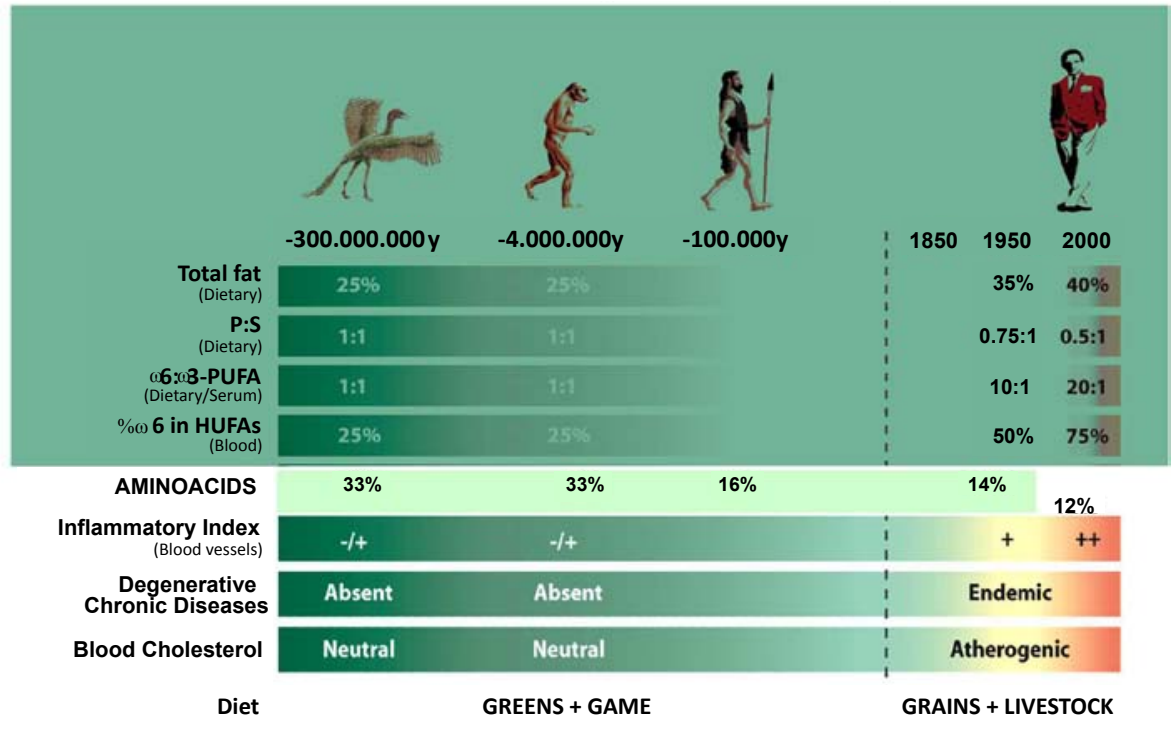

Figure 1: Nutrient intakes among Homo sapiens, Homo erectus, hunter gatherers and Homo economicus men [3].

\begin{tabular}{|c|c|c|c|c|c|}
\hline Causes of Death & Prudent Diet Western & Western Type Diet & Total Foods & Score & w-6/w-3 Ratio \\
\hline$n=1385$ & \multicolumn{5}{|c|}{ Men (Mean \pm Standard deviation) g/day } \\
\hline Injury-accidents $(n=215)$ & $892 \pm 252$ & $202 \pm 22$ & $1094 \pm 302$ & $7.93 \pm 2.831$ & $31.3 \pm 5.3$ \\
\hline Communicable Diseases. $(n=372)$ & $806 \pm 237$ & $256 \pm 28$ & $1062 \pm 198$ & $7.26 \pm 2.7$ & $38.2 \pm 6.6$ \\
\hline \multicolumn{6}{|l|}{ NCDs } \\
\hline Malignant $(n=77)$ & $715 \pm 241$ & $412 \pm 53$ & $1127 \pm 311$ & $6.44 \pm 2.5$ & $42.2 \pm 6.8$ \\
\hline Circulatory $(n=406)$ & $757 \pm 245$ & $437 \pm 47$ & $1194 \pm 318$ & $6.81 \pm 2.6$ & $45.3 \pm 8.3$ \\
\hline Chronic lung diseases (97) & $705 \pm 202$ & $405 \pm 41$ & $1110 \pm 302$ & $6.25 \pm 2.2$ & $42.0 \pm 7.4$ \\
\hline Kidney diseases $(n=163)$ & $617 \pm 188$ & $505 \pm 55$ & $1122 \pm 325$ & $5.72 \pm 1.8$ & $41.8 \pm 6.1$ \\
\hline Diabetes $(n=23)$ & $605 \pm 175$ & $522 \pm 61$ & $1127 \pm 334$ & $5.65 \pm 1.7$ & $41.6 \pm 5.7$ \\
\hline Kendall's t & $0.045^{*}$ & $0.048^{* *}$ & 0.025 & $0.041^{*}$ & $0.042^{*}$ \\
\hline$n=837$ & \multicolumn{5}{|c|}{ Women (Mean \pm Standard deviation) g/day } \\
\hline Injury-accidents $(n=139)$ & $822 \pm 234$ & $186 \pm 23$ & $1008 \pm 224$ & $8.40 \pm 2.2$ & $25.5 \pm 5.7$ \\
\hline Communicable diseases $(n=194)$ & $736 \pm 237$ & $218 \pm 33$ & $954 \pm 201$ & $7.51 \pm 1.9$ & $34.5 \pm 5.6$ \\
\hline \multicolumn{6}{|l|}{$\operatorname{NCDs}(n=502)$} \\
\hline Malignant $(n=54)$ & $657 \pm 197$ & $305 \pm 35$ & $962 \pm 221$ & $6.70 \pm 1.8$ & $41.6 \pm 6.8$ \\
\hline Circulatory $(n=240)$ & $655 \pm 205$ & $332 \pm 41$ & $987 \pm 218$ & $6.68 \pm 1.7$ & $44.5 \pm 7.5$ \\
\hline Chronic lung diseases $(n=95)$ & $660 \pm 180$ & $382 \pm 48$ & $1029 \pm 180$ & $6.12 \pm 1.3$ & $40.0 \pm 6.5$ \\
\hline Renal diseases $(n=87)$ & $565 \pm 155$ & $380 \pm 130$ & $995 \pm 165$ & $5.57 \pm 1.1$ & $39.7 \pm 6.8$ \\
\hline Diabetes $(n=26)$ & $553 \pm 146$ & $387 \pm 135$ & $940 \pm 153$ & $5.53 \pm 1.1$ & $40.0 \pm 6.5$ \\
\hline Kendall's $\mathrm{t}$ & $0.041^{*}$ & $0.067^{* *}$ & 0.024 & $0.043^{*}$ & $0.041^{*}$ \\
\hline
\end{tabular}

Values are mean (Standard deviation), ${ }^{*}=\mathrm{P}<0.01,{ }^{* *}=\mathrm{P}<0.001$. by comparison of food consumption among victims dying due to NCDs and with victims dying of injury and accidents among both sexes [4].

Table 1: Food Intakes and w-6/w-3 Fatty Acid Ratio of Diet in Relation to Causes of Death Based on Assessment by Dietary Diaries of the Spouse and Questionnaires Filled by the Nutritionist. 
Citation: Takahashi T, Singh RB, Meester FD, Wilson D (2013) How the 'West' can Overcome Unhealthy Behaviours to Prevent Chronic Diseases. J Socialomics 2: e114. doi:10.4172/2167-0358.1000e114

development goals and for sustainable human development [12-14]. Perhaps we need another well-intentioned well-known McGovern Report but this time instead of being exploited deals with the ecological epidemiology of dietary intake and affordable functional food that is focussed on health for all and a reduction of social inequality.

There is need to educate the food industry to develop functional foods characterized with low glycemic index and optimal amount of soluble fiber, vitamins, minerals, antioxidants, essential and nonessential amino acids and a balanced ratio of $w-6 / w-3$ fatty acids similar to the notional Palaeolithic diet [15-17]. These foods and nutrients rich in the Paleolithic style and Mediterranean style diets and have been found to be protective against non-communicable diseases (NCDs) [15-17]. A recent study showed that, there was a significant decrease in the prudent food consumption among victims dying due to NCDs compared to those dying due to other causes [4] (Table 1). The nutrient consumption pattern during various stages of evolution (Figure 1) indicates that NCDs are the creation of Homo economicus societies. The food industry should explore the possibility of adding these nutrients which have been reported to have NO activating effects [15-17]. Nutrients such as resveratrol and epicatechin present in wines and flavanols rich in cocoa as well as, $\mathrm{w}-3$ fatty acids can protect against adverse effects of food processing and provide additional beneficial effects on cardiovascular health, insulin resistance and memory dysfunction [14-17]. Further efforts should be made to educate the people and industry on protective effects of wines and to consider adding NO activating agents like epicatechin and flavones in alcohol to provide additional beneficial effects. Some experts (FD) from EU have proposed "Mind, Body Index= BMI" to address total health because physical, social, mental and spiritual health may depend on body composition.It is remarkable that animals including man in the wild do not suffer overweight but Homo economicus (Figure 1) do suffer [10]. Even modern husbandry animals do not do so. This is in contrast to companion pets. The human part-the mind-appears responsible for the disease due to poor social, mental and spiritual health. It is important to analyze facts as primary and secondary risk factors. Food is here secondary. It contributes, yet not causes the problem. Just as cholesterol contributes, but does not cause heart disease (www.columbus-concept. com). Once understood and accepted, such a basic principle allows one to take the right decision about prevention of CVDs and other chronic diseases.

\section{References}

1. WHO (2010) Mortality and burden of disease estimates for WHO Member States in 2008. Geneva: World Health Organization.
2. Moodie R, Stuckler D, Monteiro C, Sheron N, Neal B, et al. (2013) Profits and pandemics: prevention of harmful effects of tobacco, alcohol, and ultraprocessed food and drink industries. Lancet.

3. Singh RB, Takahashi T, Nakaoka T, Otsuka K, Toda E, et al. (2013) Nutrition in transition from Homo sapiens to Homo economicus. The Open Nutra J.

4. Fedacko J, Vargova V, Singh RB, Anjum B, Takahashi T, et al. (2012) Association of high $w-6 / w-3$ fatty acid ratio diet with causes of death due to non-communicable diseases among urban decedents in North India. The Open Nutra Jour 5:113-123.

5. Sidney S, Rosamond WD, Howard VJ, Luepker RV, National Forum fo Heart Disease and Stroke Prevention (2013) The "Heart Disease and Stroke Statistics-2013 Update" and the Need for a National Cardiovascular Surveillance System. Circulation 127:21-23.

6. U. S. Health in International Perspective: Shorter Lives, Poorer Health (2013) National Academy of Sciences, USA.

7. Wealth but not health in USA (2013) Lancet 381: 177.

8. Singh RB, Anjum B, Takahashi T, Martyrosyan DM, Pella D (2012) Poverty is not the absolute cause of deaths due to noncommuni- cable diaseses NCDs. World heart $\mathrm{J}$.

9. Marmot M, Allen J, Bell R, Bloomer E, Goldblatt P (2012) WHO European review of social determinants of health and the health divide. Lancet 380: 1011 1029

10. Singh RB, Toda E, Takahashi T, Fedacko J, Pella D, et al. (2013) Globalization of wealth but not healthy heart behaviour. World Heart J.

11. Iglehart JK (2012) Primary care update, light at end of the tunnel? N Engl Med 366: 2144-2146.

12. Horton R (2013) Non-communicable diseases: 2015 to 2025. Lancet 381:509510 .

13. Clark H (2013) NCDs: a challenge to sustainable human development. Lance 381: 510-511.

14. Keeping the Promise: United to Achieve the Millennium Development Goals

15. De Meester F (2008) Wild-type land based foods in health promotion and disease prevention. Wild Type Foods in Health Promotion and Disease Prevention 3-20.

16. Singh RB, Kumar A, Neki NS, Pella D, Rastogi SS, et al. (2011) Diet and Lifestyle Guidelines and Desirable Levels of Risk Factors for Prevention of Cardiovascular Disease and Diabetes among Elderly Subjects. World Heart J 3:305-320.

17. Hristova K, Nakaoka T, Otsuka K, Fedacko J, Singh R, et al. (2012) Perspectives on Chocolate Consumption and Risk of Cardiovascular Dis-ease and Cognitive Function. The Open Nutraceuticals Journal 5: 207-212. 